\title{
PRINCIPAIS MÉTODOS DE CARACTERIZAÇÃo DA POROSIDADE DE RESINAS À BASE DE DIVINILBENZENO
}

\author{
Viviane Gomes Teixeira \\ Departamento de Química - Instituto de Ciências Exatas - Universidade Federal Rural do Rio de Janeiro, Seropédica, RJ \\ Instituto de Macromoléculas Professora Eloisa Mano - Universidade Federal do Rio de Janeiro, Rio de Janeiro, RJ \\ Fernanda M. B. Coutinho* \\ Instituto de Macromoléculas Professora Eloisa Mano - Universidade Federal do Rio de Janeiro, Rio de Janeiro, RJ \\ Departamento de Processos Industriais - Instituto de Química - Universidade do Estado do Rio de Janeiro, Rio de Janeiro, RJ \\ Ailton S. Gomes \\ Instituto de Macromoléculas Professora Eloisa Mano - Universidade Federal do Rio de Janeiro, Rio de Janeiro, RJ \\ Recebido em 7/8/00; aceito em 11/4/01

\begin{abstract}
THE MOST IMPORTANT METHODS FOR THE CHARACTERIZATION OF POROSITY OF STYRENE-DIVINYLBENZENE BASED RESINS. This paper reviews the most important methods used to characterize the porosity of styrene-divinylbenzene resins. Methods such as adsorption of nitrogen for determination of surface area and mercury intrusion porosimetry for characterization of pore size distribution are related.
\end{abstract}

Keywords: divinylbenzene based resins; porous structure; characterization

\section{INTRODUÇÃOO}

A separação de íons metálicos é, há muito, um problema que vem ocupando os pesquisadores de todo o mundo, sem que, até hoje, os métodos desenvolvidos sejam considerados satisfatórios. Com o aumento do uso de metais de difícil separação e seus compostos em tecnologias de ponta, torna-se cada vez mais necessária a produção de materiais com elevada pure$\mathrm{za}^{1,2}$.

A cromatografia de extração vem sendo bastante utilizada na separação de íons metálicos. Nesse método, são utilizados suportes funcionalizados com grupamentos quelantes ou impregnados com agentes complexantes líquidos. Os suportes mais utilizados são os copolímeros reticulados à base de divinilbenzeno, devido à facilidade de obtenção desses materiais com estrutura porosa controlada. Vários estudos têm sido feitos na tentativa de se obter suportes com esqueleto polimérico de estrutura favorável à reação de complexação, ou seja, uma distribuição adequada dos grupos quelantes na superfície da rede polimérica. A obtenção de suportes com alta área específica e diâmetros de poro altos leva a uma rápida difusão dos íons e conseqüente melhora da cinética de extração, assim como a um aumento da capacidade total de complexação ${ }^{3}$.

Suportes poliméricos impregnados exigem um balanço entre o diâmetro de poro e o grau de impregnação, ou seja, o teor de agente complexante adsorvido na superfície do suporte. Copolímeros com alto grau de impregnação devem ser sintetizados em condições tais que produzam poros com diâmetro médio relativamente alto, a fim de favorecer a melhor distribuição do agente complexante. Para baixos graus de impregnação, poros pequenos já são capazes de propiciar uma boa distribuição. Porém, poros muito pequenos, além de prejudicar a distribuição do agente complexante, impedem a difusão satisfatória do meio diluente através do esqueleto polimérico, dificultando assim a reação de complexação ${ }^{4}$.

A utilização de suportes funcionalizados, onde o grupamento quelante esteja quimicamente ligado à rede polimérica, torna ainda mais necessária a obtenção de estruturas porosas

\footnotetext{
*e-mail: fern@uerj.bre fern@ima.ufrj.br
}

adequadas, já que a capacidade desses suportes é função da distribuição dos grupos no esqueleto polimérico. Devido à sua baixa mobilidade, esses grupos geralmente não saturam a esfera de coordenação dos íons metálicos, pois as moléculas rígidas do polímero não assumem a conformação adequada para tal, podendo haver formação de complexos insaturados de menor estabilidade ${ }^{5,6}$.

Devido ao balanço entre a estrutura porosa e o desempenho de suportes poliméricos em métodos cromatográficos, o mecanismo de formação da estrutura porosa de copolímeros à base de divinilbenzeno vem sendo bastante estudado desde a década de $60^{7-10}$. Para tal, é fundamental o conhecimento e a utilização de técnicas específicas de caracterização da porosidade dos materiais obtidos.

\section{CARACTERIZAÇÃO DA ESTRUTURA POROSA}

Quando uma solução aquosa de íons metálicos permeia através de uma coluna cromatográfica empacotada com um material polimérico, a reação de extração dos íons se dá somente na superfície da fase estacionária, já que a água é incapaz de inchar a rede polimérica. Este fato faz com que seja adequado introduzir-se o termo "adsorção" no tratamento deste processo de retenção, já que se trata apenas de um fenômeno de superfície, apesar de ser acompanhado por uma reação química.

A área de uma determinada massa de sólido é inversamente proporcional ao tamanho de suas partículas. Considerando-se o caso ideal de partículas cúbicas homogêneas com vértices de comprimento $\ell$, a área específica $A$, designada como sendo a área de $1 \mathrm{~g}$ do sólido, é dada por:

$$
A=6 / \rho \ell
$$

(Equação 1)

onde $\rho$ é a densidade do sólido. Para sólidos de forma irregular e diferentes tamanhos de partícula essa relação se torna mais complexa, porém ainda pode ser usada como um indicativo da relação entre a área e o tamanho da partícula.

Existem dois tipos diferentes de formação porosa. O primeiro tipo se constitui de espaços existentes entre as partículas primárias de um sólido quando estas se encontram ligadas pela ação de forças de superfície, formando agregados ou aglomera- 
dos. Estes conjuntos de partículas são denominados partículas secundárias. Fazem parte ainda deste primeiro tipo de poros os espaços existentes entre as partículas secundárias. As características desse sistema de poros estão ligadas à forma e ao tamanho das partículas primárias e secundárias do sólido que o originou. As principais formas de partículas primárias são a esférica e a plana. A forma dos poros formados a partir da aglomeração dessas partículas será função da sua distribuição de tamanhos e da forma de empacotamento. Quando as partículas são esféricas, que é o caso dos suportes poliméricos à base de divinilbenzeno obtidos por polimerização em suspensão, o empacotamento pode ser expresso em termos do número de coordenação $N$, que é o número médio de partículas esféricas vizinhas em contato com uma determinada partícula (Figura 1). No caso ideal, onde as esferas apresentam o mesmo tamanho, $N$ pode assumir valor igual a 12 se o empacotamento for hexagonal, 4 para tetragonal e pode chegar a 2 em uma estrutura muito aberta.

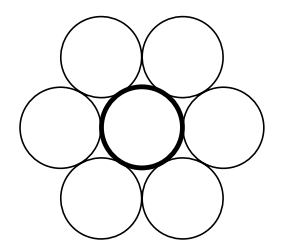

Figura 1. Poros em agregados constituídos de partículas esféricas $^{11}$.

O segundo tipo de porosidade é formado quando uma parte do sólido é removida, seja por um processo de solubilização parcial deste sólido, reações com formação e permeação de gases ou, no caso dos suportes poliméricos, pela separação de fases entre o copolímero e o diluente durante o processo de síntese do suporte (processo de polimerização). Estes dois tipos de porosidade são responsáveis pelos conceitos de área externa e interna.

A área externa é caracterizada pela porosidade constituída pelos espaços existentes entre partículas primárias e entre partículas secundárias. Este tipo de área aumenta quando a superfície do sólido apresenta imperfeições na forma de sulcos e fissuras com dimensões maiores em comprimento do que em profundidade. Já a área interna é formada pelas paredes dos sulcos, poros e cavidades com profundidades maiores do que o comprimento e que tenham abertura para o exterior. Poros fechados não contribuem para o aumento da área interna. Normalmente, a área interna é muito maior que a externa, sendo determinante da superfície total do sólido ${ }^{11,12}$.
Parâmetros relacionados ao aumento da superfície de contato entre a fase estacionária e a fase móvel são de extrema importância na otimização do processo de adsorção. Dentre os principais parâmetros utilizados na caracterização da estrutura porosa citam-se densidade, tamanho de partícula, área específica, tamanho e volume de poros. Várias técnicas foram desenvolvidas para a determinação quantitativa desses parâmetros, sendo normalmente associadas para a obtenção de resultados conclusivos sobre a porosidade de um material. Este trabalho dedica-se a rever a aplicação de dois dos principais métodos utilizados na caracterização da porosidade de copolímeros à base de divinilbenzeno, que são a adsorção de nitrogênio e a intrusão de mercúrio

\section{Área Específica}

Um dos métodos mais comuns de determinação da área específica de um sólido se baseia na determinação da quantidade de um adsorvato necessária para recobrir com uma monocamada a superfície de um adsorvente. Os adsorvatos normalmente utilizados para esse fim são gases e, por isso, torna-se necessário o estudo da interação entre o gás e o sólido no processo de adsorção.

Quando um sólido é exposto a um gás ou vapor em um sistema fechado à temperatura constante, o sólido passa a adsorver o gás, ocorrendo assim um aumento da massa do sólido e um decréscimo da pressão do gás. Após um determinado tempo, a massa do sólido e a pressão do gás assumem um valor constante. A quantidade de gás adsorvida pode ser calculada pela diminuição da pressão por meio da aplicação das leis dos gases ou pela massa de gás adsorvida pelo sólido.

A quantidade de gás adsorvida é função da interação entre o gás e o sólido, sendo portanto dependente da natureza dessas espécies. O processo de adsorção pode ser classificado como um processo físico ou químico, dependendo do tipo de força envolvido. A adsorção física, também denominada adsorção de van der Waals, é causada por forças de interação entre as moléculas. Este processo pode ser comparado com a condensação de vapor para formação de um líquido, que só é importante a temperaturas abaixo da temperatura crítica do gás. A adsorção química ou quimissorção envolve interações específicas entre o adsorvente e o adsorvato com energia quase tão alta quanto a de formação de ligações químicas ${ }^{11,13}$. A Tabela 1 mostra as principais diferenças entre os dois tipos de adsorção.

A adsorção física de um gás em um sólido é o resultado de forças de atração entre as moléculas individuais do gás e os átomos ou íons presentes na composição do sólido. Essas forças incluem forças de dispersão, que apresentam um efeito de atração, e forças repulsivas de baixa intensidade.

Tabela 1. Principais diferenças entre adsorção física e adsorção química ${ }^{14}$.

\begin{tabular}{ll}
\hline Adsorção física & Adsorção química \\
\hline$>$ Causada por forças de van der Waals. & $>$ Causada por forças eletrostáticas e ligações covalentes. \\
$>$ Não há transferência de elétrons. & $>$ Há transferência de elétrons. \\
$>$ Calor de adsorção $=2-6 \mathrm{kcal} / \mathrm{mol}$. & $>$ Calor de adsorção $=10-200 \mathrm{kcal} / \mathrm{mol}$. \\
$>$ Fenômeno geral para qualquer espécie. & $>$ Fenômeno específico e seletivo. \\
$>$ A camada adsorvida pode ser removida por aplicação de & $>$ A camada adsorvida só é removida por aplicação de vácuo \\
vácuo à temperatura de adsorção. & e aquecimento a temperatura acima da de adsorção. \\
$>$ Formação de multicamadas abaixo da temperatura crítica. & $>$ Somente há formação de monocamadas. \\
$>$ Acontece somente abaixo da temperatura crítica. & $>$ Acontece também a altas temperaturas. \\
$>$ Lenta ou rápida. & $>$ Instantânea. \\
$>$ Adsorvente quase não é afetado. & $>$ Adsorvente altamente modificado na superfície.
\end{tabular}


As forças de dispersão, caracterizadas por London, têm sua origem na rápida flutuação da densidade eletrônica de cada átomo, que induz um momento elétrico entre átomos vizinhos fazendo com que estes se atraiam. A Equação 2 mostra a expressão para o cálculo da energia potencial de dois átomos isolados separados por uma distância $r$ :

$$
\varepsilon_{D}(r)=-C_{1} r^{-6}-C_{2} r^{-8}-C_{3} r^{-10} \quad \text { (Equação 2) }
$$

onde os coeficientes $\mathrm{C}_{1}, \mathrm{C}_{2}$ e $\mathrm{C}_{3}$ são constantes de dispersão associadas a momentos instantâneos dos tipos dipolo-dipolo, dipolo-quadrupolo e quadrupolo-quadrupolo, respectivamente. Por serem muito pequenos, os dois últimos termos são normalmente negligenciados, sendo a equação reduzida a:

$$
\varepsilon_{D}(r)=-C_{1} r^{-6}
$$

(Equação 3)

As forças repulsivas, originadas a partir da interpenetração das nuvens eletrônicas de dois átomos, podem ter sua energia potencial calculada pela Equação 4 ou pela Equação simplificada 5:

$$
\begin{array}{cl}
\varepsilon_{R}(r)=B \exp (-a r) & (\text { Equação 4) } \\
\varepsilon_{r}(r)=B r^{-\mathrm{m}} & (\text { Equação 5) }
\end{array}
$$

onde $B$ e $a$ são constantes. O índice $m$ na Equação 5 normalmente assume o valor 12. A energia potencial total entre dois átomos, também chamada potencial de Lennard-Jones, é então dada por:

$$
\varepsilon(r)=-C_{1} r^{-6}+B r^{-12}
$$

Existem várias relações desenvolvidas para o cálculo do parâmetro $C_{1}$. Todas, porém, levam em consideração as propriedades dos átomos como polarizabilidade, suscetibilidade magnética e número de elétrons por átomo envolvido na interação mútua. $\mathrm{O}$ efeito da polaridade na energia de interação leva à classificação da adsorção em adsorção não-específica, onde somente forças de dispersão e repulsivas estão envolvidas, ou adsorção específica, onde, além destas, estão também presentes forças eletrostáticas. De acordo com esta classificação, os adsorventes e adsorvatos foram divididos em grupos que, associados, levam a um tipo ou outro de adsorção. Dentre os adsorventes mais comuns, o nitrogênio e o argônio são os mais usados em estudos de adsorção, pois apresentam sempre adsorção não-específica com qualquer tipo de sólido ${ }^{11,14}$.

Quando o estudo do fenômeno de adsorção é feito com o objetivo de se obter informações sobre a área específica e a estrutura porosa de um sólido, a construção de uma isoterma de adsorção é de fundamental importância, pois sua forma revela muitos detalhes sobre as características do material. A isoterma mostra a relação entre a quantidade molar de gás $n$ adsorvida ou dessorvida por um sólido, a uma temperatura constante, em função da pressão do gás. Por convenção, costuma-se expressar a quantidade de gás adsorvida pelo seu volume $V_{a}$ em condição padrão de temperatura e pressão $\left(0^{\circ} \mathrm{C}\right.$ e 760 torr), enquanto que a pressão é expressa pela pressão relativa $P / P_{0}$, ou seja, a relação entre a pressão de trabalho e a pressão de vapor do gás na temperatura utilizada.

$O$ formato da isoterma é função do tipo de porosidade do sólido. Várias são as formas de isotermas conhecidas até hoje porém, todas são variações de seis tipos principais. Os cinco primeiros tipos foram primeiramente sugeridos por Brunauer em 1938, sendo o sexto tipo proposto mais tarde. A Figura 2 mostra os seis tipos de isotermas.

A isoterma do tipo I é característica de sólidos com microporosidade. As isotermas do tipo II e IV são típicas de sólidos não porosos e de sólidos com poros razoavelmente grandes,

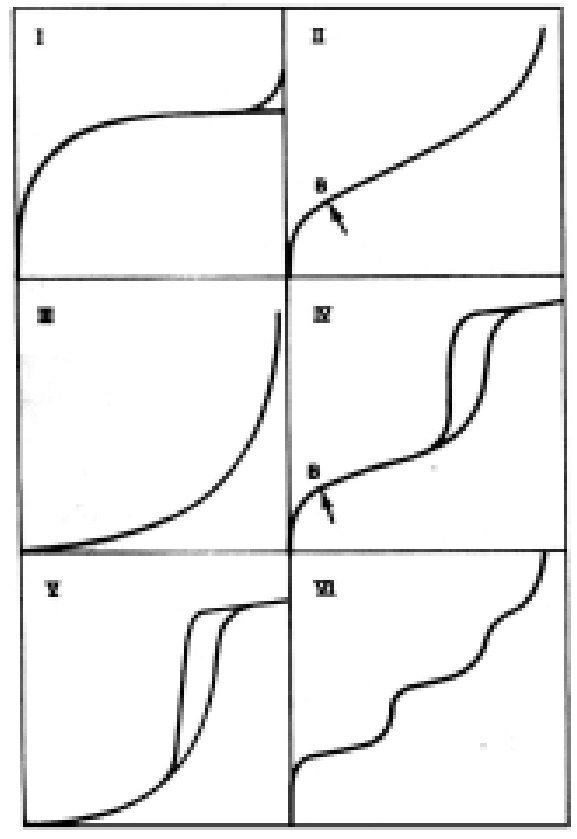

Figura 2. Isotermas (n versus $\mathrm{P} / \mathrm{P}_{0}$ ) do tipo I ao tipo $V I^{11}$.

respectivamente. As isotermas do tipo III e V são características de sistemas onde as moléculas do adsorvato apresentam maior interação entre si do que com o sólido. Estes dois últimos tipos não são de interesse para a análise da estrutura porosa. A isoterma do tipo VI é obtida através da adsorção do gás por um sólido não poroso de superfície quase uniforme, o que representa um caso muito raro entre os materiais mais comuns $^{15}$.

Pode-se perceber que o tipo de isoterma é função do efeito do tamanho do poro sobre o fenômeno de adsorção. De acordo com as curvas conhecidas, foi estabelecida uma classificação dos poros em função de seu diâmetro (Tabela 2), já que este é seu principal parâmetro dimensional ${ }^{11}$.

Tabela 2. Classificação dos poros segundo seu diâmetro ${ }^{11}$

\begin{tabular}{cc}
\hline Classificação & Diâmetro $(\AA)$ \\
\hline Microporo & $\phi<20$ \\
Mesoporo & $20<\phi<500$ \\
Macroporo & $\phi>500$ \\
\hline
\end{tabular}

Nas isotermas dos tipos IV e V, são observados dois ramos distintos. $\mathrm{O}$ inferior mostra a quantidade de gás adsorvida com o aumento da pressão relativa, enquanto que o ramo superior representa a quantidade de gás dessorvida no processo inverso. Esses dois tipos de isotermas são característicos de sólidos mesoporosos e macroporosos, nos quais o processo de evaporação é diferente do processo de condensação. Quando a condensação se dá dentro dos poros, onde as forças de atração são maiores devido à proximidade entre as moléculas, esta pode ocorrer a pressões menores do que em sólidos não porosos. A evaporação, porém, é dificultada pelo formato do poro. Os diferentes caminhos caracterizam uma histerese entre os processos de adsorção e dessorção. A isoterma do tipo IV nada mais é do que a isoterma do tipo II com o fenômeno de histerese, que será mais pronunciado quanto maior for a dispersão de tamanhos de poro. A ausência de histerese não significa a ausência de porosidade, já que alguns formatos de poro podem levar a processos iguais de adsorção e dessorção ${ }^{15}$. 
Para sólidos microporosos, a isoterma do tipo I mostra um ramo quase vertical na primeira região da curva. Isto se deve à grande facilidade de adsorção em poros com diâmetros menores que $20 \AA$ A. Após o preenchimento dos microporos, que acontece em ordem crescente de tamanho, praticamente não há outras regiões onde a adsorção seja significativa. A curva portanto mostra uma região quase constante que volta a crescer quando o fenômeno de condensação começa a ocorrer.

A isoterma do tipo II, originada a partir da adsorção em um sólido não poroso, mostra um aumento rápido da quantidade de gás adsorvida para valores baixos de pressão relativa, que se torna mais lento para valores intermediários de $P / P_{0}$. Este comportamento se deve à forte interação das primeiras moléculas de gás com os sítios mais ativos do sólido. Após o preeenchimento desses sítios, o gás passa a interagir com os de mais baixa energia. Isso é visualizado pela menor inclinação da região central da isoterma. Na região final da curva ocorre um aumento rápido da quantidade de gás adsorvida em função da pressão relativa. Isso se deve ao início da formação de camadas múltiplas e posterior condensação. Informações sobre a área do sólido são extraídas a partir da primeira região da curva, ou seja, da região onde se tem a formação de uma monocamada.

Com o objetivo de se obter informações sobre as características porosas, principalmente sobre a área de um sólido a partir da isoterma de adsorção, vários métodos foram desenvolvidos com base em modelos empíricos e teóricos ${ }^{15}$.

A primeira teoria que relaciona a quantidade de gás adsorvida com a pressão de equilíbrio do gás foi proposta por Langmuir em 1918. Essa teoria deveria ser aplicada principalmente a sistemas envolvendo adsorção química, já que se limita em considerar apenas a formação de uma monocamada do gás. O fenômeno de adsorção é atribuído à colisão não-elástica entre as moléculas do gás e a superfície do sólido. Esse fato permite a formação da monocamada por um pequeno intervalo de tempo limitado pelo retorno do adsorvato à fase gasosa. Considerando que a adsorção é função apenas de forças que atuam a pequenas distâncias, a formação de camadas subseqüentes de gás é impedida pela primeira camada. Essa promove a colisão elástica de outras moléculas do gás, que retornam à fase gasosa. $\mathrm{O}$ modelo matemático considera que o número de moléculas que evaporam da superfície do sólido é igual ao numéro de moléculas que condensam sobre essa superfície. O número de moléculas de gás $(Z)$ que colidem em uma unidade de área por unidade de tempo é dado por:

$$
Z=P /(2 \pi m k T)^{1 / 2}
$$

(Equação 7)

onde $k$ é a constante de Boltzmann, $m$ a massa de uma molécula, $P$ a pressão e $T$ a temperatura absoluta.

O número de moléculas que evaporam depende da força que as ligam à superfície do sólido. O tempo de residência de uma molécula pode ser dado em função da energia $Q$, envolvida quando uma molécula é adsorvida, e do tempo de vibração molecular $\tau_{0}$ pela Equação 8.

$$
\tau=\tau_{0} \exp (Q / R T)
$$

(Equação 8)

O número de moléculas que evaporam de uma unidade de área por unidade de tempo é igual a $1 / \tau$. Se $\theta$ é a fração de área coberta a uma pressão $P$, a velocidade de evaporação nessa área será igual à velocidade de adsorção sobre uma área $(1-\theta)$ e será dada por:

$$
\left[P /(2 \pi m k T)^{1 / 2}\right] \alpha_{0}(1-\theta)=\left[1 / \tau_{0} \exp (-Q / R T)\right] \theta \quad(\text { Equação 9) }
$$

onde o coeficiente de condensação $\alpha_{0}$ é a razão entre o número de colisões elásticas e o total de colisões na superfície do sólido.
Se $V$ é a quantidade de gás adsorvida a uma pressão $P$ e $V_{m}$ é a capacidade da monocamada, ou seja, a quantidade de gás necessária para formar a monocamada, então:

$$
\theta=V / V_{m}=b P /(1+b P)
$$

onde $b=\alpha_{0} \tau_{0} /(2 \pi m k T)^{1 / 2} \cdot \exp (Q / R T)$

Essa expressão pode ser escrita na forma da equação de uma reta. $\mathrm{O}$ gráfico de $P / V$ versus $P$, pode fornecer a capacidade da monocamada $V_{m}$. A área específica ocupada pela monocamada pode ser obtida conhecendo-se a área ocupada por uma molécula do gás $\sigma$ pela Equação 11 .

$$
A=N \sigma V_{m} / M_{v}
$$

(Equação 11)

onde $\mathrm{N}$ é o número de Avogadro e $M_{v}$, o volume molar. No caso onde nitrogênio é utilizado como adsorvente, a área $A$ é dada por $4,35 V_{m}^{13}$.

Langmuir considerou também a possibilidade da formação de camadas múltiplas através do mecanismo de evaporação e condensação, porém a equação para a isoterma por ele derivada era muito complexa. Na década de 30, Brunauer, Emmett e Teller derivaram uma equação para a adsorção de gases em multicamadas na superfície de sólidos. A equação, denominada BET (letras iniciais dos nomes dos três autores), se baseia na hipótese de que as forças responsáveis pela condensação do gás são também responsáveis pela atração de várias moléculas para a formação de multicamadas. Brunauer, Emmett e Teller generalizaram a equação de Langmuir considerando que a velocidade de condensação das moléculas da fase gasosa sobre a primeira camada é igual à velocidade de evaporação da segunda camada, isto é:

$$
a_{2} P A_{1}=b_{2} A_{2} \exp \left(-Q_{2} / R T\right)
$$

(Equação 12)

onde:

$P=$ pressão;

$A_{1}$ e $A_{2}=$ área coberta por 1 e 2 camadas de moléculas de gás, respectivamente

$Q_{2}=$ calor de adsorção da segunda camada

$a_{2}=\alpha_{1} /(2 \pi m k T)^{1 / 2}$ (constante);

$b_{2}=1 / \pi($ constante)

Generalizando para duas camadas subseqüentes (i - 1) e i, tem-se:

$$
a_{\mathrm{i}} P A_{i-1}=b_{\mathrm{i}} A_{\mathrm{i}} \exp \left(-Q_{\mathrm{i}} / R T\right)
$$

A área específica total do sólido será dada por:

$$
A=\sum_{i=0}^{i=\infty} A_{i}
$$

e o volume total de gás adsorvido por:

$$
V=V_{0} \sum_{i=0}^{i=\infty} i A_{i}
$$

onde $V_{0}$ é o volume de gás adsorvido por unidade de área para formar uma monocamada completa. Dividindo-se a Equação 15 pela Equação 14, tem-se $\mathrm{e}^{11,13}$ :

$$
V / A V_{0}=V / V_{\mathrm{m}}=\sum_{i=0}^{i=\infty} i A_{i} / \sum_{i=0}^{i=\infty} A_{i}
$$

(Equação 16)

Em princípio, cada camada tem valores próprios para parâmetros como $a$ e $Q$, entre outros. Portanto, o somatório apresentado pela Equação 16 só pode ser feito se algumas 
aproximações forem consideradas. Tais aproximações assumem que: (a) em todas as camadas, exceto na primeira, o calor de adsorção $\left(\mathrm{Q}_{2}, \mathrm{Q}_{3}, \ldots \mathrm{Q}_{\mathrm{n}}\right)$ é igual ao calor molar de condensação (QL); (b) as condições de evaporação e condensação são idênticas, isto é, $b_{2} / a_{2}=b_{3} / a_{3}=\ldots=b_{n} / a_{n}$ em camadas subseqüentes à primeira e (c) quando $\mathrm{P}=\mathrm{P}_{0}$ (pressão de saturação do vapor na temperatura de adsorção), o número de camadas é infinito. Desconsiderando o longo desenvolvimento matemático deste somatório, obtém-se finalmente a expressão denominada equação de BET:

$$
P / V\left(P_{0}-P\right)=1 / V_{\mathrm{m}} c+\left[(c-1) / \mathrm{V}_{\mathrm{m}} c\right] P / P_{0}(\text { Equação } 17)
$$

onde $c=\exp \left[\left(Q_{1}-Q_{\mathrm{L}}\right) / R T\right]$.

O gráfico de $P / V\left(P_{0}-P\right)$ versus $P / P_{0}$ dá origem a uma reta de coeficiente angular igual a $(c-1) / V_{\mathrm{m}} c$ e coeficiente linear igual a $1 / V_{\mathrm{m}} c$. Essa expressão pode descrever as isotermas dos tipos I, II e III, dependendo da magnitude da contante $c$. Se $c$ apresentar um valor maior que 2, a Equação 17 dará origem a uma curva com o formato da isoterma do tipo II. Quanto maior for o valor de $c$, mais pronunciada será a curvatura na primeira região da curva, o que torna mais fácil a determinação do valor de $V_{\mathrm{m}}$, pois a parte reta da curva é mais facilmente encontrada (Figura 3). A Figura 3 mostra que quando $c$ excede o valor 2, a curva passa a apresentar um ponto de inflexão, que se aproxima do ponto onde a quantidade de gás adsorvida é igual à capacidade da monocamada dada pela equação de BET. À medida que $c$ assume valores menores que 2, mas ainda positivos, a curva começa a assumir o formato da isoterma do tipo III (curva A), onde não se percebe mais o ponto de inflexão. Altos valores de $c$ podem ser obtidos quando nitrogênio é utilizado como adsorvente, o que leva à preferência da utilização deste gás para a maioria dos sólidos.

Considerando que $c$ seja muito maior que 1 , o termo $1 / V_{\mathrm{m}} c$ aproxima-se de zero e $(c-1)$ pode ser considerado igual a $c$. A Equação de BET assume, portanto, a forma aproximada da Equação 18 , denominada relação de um ponto (single point). Por meio dessa relação, pode-se construir uma reta de origem $(0,0)$ e inclinação $1 / \mathrm{V}_{\mathrm{m}}$ conhecendo-se apenas um único ponto ${ }^{15}$.

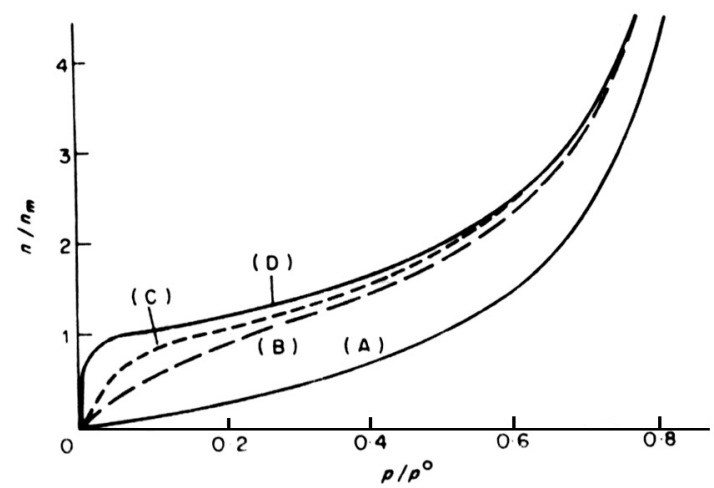

Figura 3. Curvas calculadas a partir da equação de BET para: (A) $c=1$; (B) $c=11 ;(C) c=100 ;$ (D) $c=10.000$, onde $n /$ $n_{m}$ é equivalente a $\mathrm{V} / \mathrm{V}_{m}{ }^{11}$.

$$
P / V\left(P_{0}-P\right)=\left(1 / \mathrm{V}_{\mathrm{m}}\right) P / P_{0} \quad \text { (Equação 18) }
$$

A utilização da forma aproximada da equação de BET é avaliada considerando-se a aceitação do erro a ela associada. Normalmente, para se obter valores aproximados de área, a rapidez desse método se torna uma vantagem que se sobrepõe ao erro considerado.
A forma não aproximada da equação de BET é a mais aplicada a dados experimentais. O volume da monocamada $V_{\mathrm{m}}$ pode ser calculado pela resolução do sistema:

$$
b=1 / V_{\mathrm{m}} c \text { e } a=(c-1) / V_{\mathrm{m}} c
$$

onde $b$ é o coeficiente linear e $a$ o coeficiente angular da reta obtida.

A equação de BET foi desenvolvida com o objetivo de relacionar valores obtidos a partir das isotermas de adsorção com a área específica de um sólido. Para tal, obtém-se o volume da monocamada $V_{\mathrm{m}}$ através do volume de gás adsorvido $V$ a uma determinada pressão (Equação 19). A área $A$ pode então ser calculada pela Equação 11. Todo o tratamento matemático desenvolvido leva em consideração a formação de multicamadas, porém, observou-se que a equação não é valida em toda a faixa de valores de pressão. A relação linear só é obedecida, para a maioria dos sistemas adsorvente/adsorvato, na faixa de valores de pressão relativa entre 0,05 e 0,35 . O valor máximo dessa faixa determina o ponto onde começa a formação de camadas múltiplas. Mesmo em sistemas com valores de $c$ altos, para os quais o início da formação da multicamada é bastante evidente, a faixa de validade da equação se mantém a mesma, diminuindo quando $c$ assume valores menores que 100 ou maiores que $200^{11}$.

Vários tentativas têm sido feitas com o intuito de modificar a equação de BET de forma que esta se aplique à região de multicamadas ${ }^{11,16}$. Brunauer ${ }^{17}$, um de seus autores, propôs a inserção do coeficiente $k$, assumindo que o número de camadas é finito na pressão de saturação $P_{0}$ e que a relação $V / V_{\mathrm{m}}$ tende ao infinito somente a uma pressão hipotética maior do que $P_{0}$. A equação modificada mostrou-se válida na faixa de valores de pressão relativa que vai até 0,8 para $k=0,79$. A equação de MacMillan-Teller ${ }^{18}$ é uma modificação da equação de BET pela inclusão, nesta última, de efeitos de tensão superficial. Já a equação de Frenkel-Halsey-Hill ${ }^{19}$ é derivada da teoria potencial. Esta última assume que a energia de uma molécula varia na ordem inversa da distância da superfície. As duas últimas equações mostram bons resultados principalmente na faixa mais alta de pressões relativas, onde a equação de Frenkel-Halsey-Hill se ajusta até 0,95 . Everett ${ }^{20}$ propôs a substituição da pressão de saturação $P_{0}$ na equação de BET pela constante ajustável $P^{*}$, o que tornou a equação válida na faixa de valores de pressão relativa entre 0,1 a 0,75 . Redhead ${ }^{21}$ observou que a equação de MacMillan-Teller é a que se aplica a uma maior faixa de pressões relativas quando, em um dado sistema, se provoca a diminuição da pressão a partir da pressão de saturação até a pressão de formação da monocamada.

\section{Distribuição de tamanhos de poro}

A distribuição de tamanhos de poro é um parâmetro muito importante para o estudo da estrutura porosa, já que está intimamente relacionado à área total do sólido.

Vários métodos foram desenvolvidos a fim de se determinar a distribuição de poros de acordo com seu tamanho. Dentre esses citam-se a microscopia eletrônica ${ }^{12,22,23,24}$, a absorção de raios gama $^{13}$ e a picnometria com hélio ${ }^{25}$. Os dois métodos mais usados, porém, são os que utilizam a adsorção física de gases, como já mostrado na determinação de área específica, e a intrusão de mercúrio.

\section{Adsorção de nitrogênio}

A distribuição de tamanhos ou de volumes de poro em função do diâmetro de poro pode ser calculada a partir da pressão relativa na qual os poros são preenchidos com um líquido proveniente da condensação de um gás. $\mathrm{O}$ processo inverso, ou seja, a evaporação do líquido contido no poro, também pode ser utilizado. 
Sólidos mesoporosos dão origem a isotermas do tipo IV (Figura 4), onde a histerese está relacionada com diferenças entre os processos de adsorção e dessorção, como já dito anteriormente. Esse comportamento está associado ao fenômeno de condensação capilar, que justifica o aumento da adsorção em sólidos mesoporosos quando comparados a sólidos não- porosos. Em 1911, Zsigmondy definiu o fenômeno de condensação capilar como sendo a condensação de um líquido nos poros de um sólido a uma pressão relativa $P / P_{0}$ menor que a unidade. Isso se deve ao fato de que a pressão de equilíbrio sobre um menisco de formato côncavo é menor que a pressão de saturação do vapor, para uma dada temperatura ${ }^{11}$.

O fenômeno de condensação capilar pode ser utilizado na determinação da distribuição do tamanho de poros na faixa mesoporosa desde que alguma função matemática correlacione o tamanho de poro com a pressão de condensação. A relação mais utilizada para esse fim é a equação de Kelvin (Equação 20) ${ }^{15}$ :

$$
\ln \left(P / P_{0}\right)=-\left(2 \gamma M_{\mathrm{v}} \cos \theta / R T r_{\mathrm{m}}\right)
$$

(Equação 20)

onde: $P=$ pressão crítica de condensação;

$\gamma=$ tensão superficial do líquido;

$M_{\mathrm{v}}=$ volume molar do adsorvato;

$\theta=$ ângulo de contato entre o sólido e a fase condensada; $r_{\mathrm{m}}=$ raio de curvatura médio do menisco do líquido.

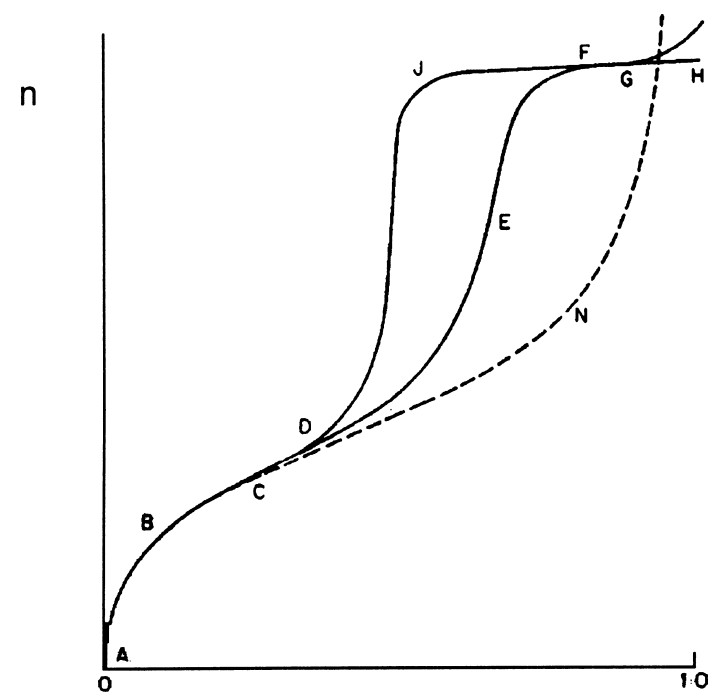

(P/Po)

Figura 4. Isotermas do tipo IV (linha contínua) e do tipo II (linha tracejada $)^{11}$.

O modelo de Zsigmondy assume que na parte inicial (ABC) da isoterma da Figura 4 a adsorção se restringe à formação de um filme fino de adsorvente nas paredes do sólido. A partir do ponto $\mathrm{D}$ começa a ocorrer condensação capilar nos poros mais estreitos. Com o aumento progressivo da pressão, os poros mais largos vão sendo preenchidos até que, quando a pressão de saturação é atingida, todos os poros já estão totalmente preeenchidos com o líquido. Assumindo-se poros de formato cilíndrico, o ângulo de contato passa a ser igual a zero (menisco hemisférico) e o raio de curvatura médio $r_{\mathrm{m}}$ se torna igual ao raio do poro $r_{\mathrm{k}}$ menos a espessura $t$ do filme formado sobre as paredes do sólido $\left(r_{\mathrm{m}}=r_{\mathrm{k}}-t\right)$. Por meio da equação de Kelvin, é possível calcular, em função da pressão relativa no ponto $\mathrm{D}$, o raio mínimo de poro onde a condensação capilar pode ocorrer. Valores de $r_{\mathrm{m}}$ podem ser convertidos para valores de raio do poro $r_{\mathrm{k}}$ por meio da Equação 21, porém é necessário conhecer o ângulo de contato real entre a fase condensada e o filme de adsorvato, já que na maioria dos casos o menisco apresenta a forma côncava $(\theta<0)$ e não a hemisférica.

$$
r_{\mathrm{k}}=r_{\mathrm{m}} \cos \theta
$$

(Equação 21)

Normalmente, o valor mínimo de diâmetro onde ocorre a condensação capilar está em torno de $10 \AA$, limite este verificado experimentalmente. O limite máximo de aplicação da equação de Kelvin é da ordem de $250 \AA$ A, determinado pela dificuldade em se medir experimentalmente decréscimos muito pequenos da pressão de vapor ${ }^{11}$.

Devido ao fenômeno de histerese, a isoterma do tipo IV apresenta dois valores de pressão relativa para cada valor de quantidade adsorvida, sendo possível, portanto, calcular dois valores diferentes para $r_{\mathrm{m}}$ a partir da equação de Kelvin. A interpretação de cada um desses valores de pressão parcial é feita por meio de um tratamento termodinâmico para os dois equilíbrios. No primeiro caso, no qual ocorre o fenômeno de adsorção, para que o vapor condense em uma pressão abaixo de sua pressão de saturação é necessária a presença de uma superfície sólida que sirva como ponto de nucleação. Em um poro, o filme de adsorvente formado nas paredes serve como tal. Portanto, a condensação do vapor é dependente da formação desse filme. Já no processo inverso de evaporação, a passagem do líquido para a fase vapor ocorre espontaneamente a partir do menisco, sendo função apenas da diminuição da pressão do sistema. Esse fato faz com que a curva de dessorção seja preferida para o cálculo do tamanho dos poros.

A ocorrência de histerese é função do formato do poro e do menisco do líquido. Para poro de formato cilíndrico fechado em uma das extremidades a condensação capilar começa no fundo do poro, formando um menisco hemisférico. A evaporação se inicia a partir desse menisco na mesma pressão que a condensação ocorreu, gerando uma isoterma sem histerese.

Já para poros cilíndricos com as duas extremidades abertas, a condensação começa nas paredes do cilindro gerando um menisco também cilíndrico e prossegue até o preenchimento total do poro. O processo de evaporação se inicia a partir das duas extremidades onde o menisco apresenta, agora, o formato hemisférico. Portanto, os dois processos não serão reversíveis entre si e uma isoterma com histerese será observada.

Um terceiro tipo de poro, comumente observado, é o de formato "pote de tinta". Este tipo é uma variação do poro cilíndrico com uma extremidade fechada, no qual a extremidade aberta apresenta um raio menor que o corpo do poro. Pode também ser encontrado com variações do diâmetro ao longo do corpo. Nesse tipo de poro o ramo inferior da curva com histerese, ou seja, o ramo de adsorção, determina o raio do corpo do poro, enquanto que o ramo de dessorção leva ao raio da extremidade aberta.

Poros com formatos cônico ou de canal em "v" dão origem a isotermas sem histerese. Poros formados por canais entre partículas se comportam como os de formato "pote de tinta", originando isotermas com histerese ${ }^{11,26}$.

Em 1951, Barret, Joyner e Halenda ${ }^{27}$ propuseram um método matemático denominado BJH que é utilizado até hoje no cálculo da distribuição dos tamanhos de poro. O método utiliza a equação de Kelvin e assume o esvaziamento progressivo dos poros cheios de líquido com o decréscimo da pressão. Pode ser aplicado tanto ao ramo de adsorção como ao de dessorção da isoterma, desde que o descréscimo da pressão se inicie do ponto onde os poros sejam considerados totalmente preenchidos, normalmente para $P / P_{0}$ igual a 0,95 ou uma pressão igual a $95 \%$ da pressão de saturação.

A quantidadade de adsorvato evaporada a cada decréscimo de pressão, após conversão de volume de gás para volume de líquido, representa o volume de poro sem considerar o filme de 
adsorvente nas paredes do sólido. A espessura $t$ do filme pode ser calculada pela Equação de Harkins \& Jura (Equação 22) ${ }^{28}$ :

$$
t=\left[13,90 /\left(0,034-\log \left(P_{0} / P\right)\right)\right]^{1 / 2} \quad(\text { Equação 22) }
$$

onde os valores numéricos são valores estatísticos que podem variar de acordo com o adsorvente utilizado. Outras equações foram também derivadas para fornecer valores de $t$, porém a equação de Harkins \& Jura é a mais utilizada ${ }^{15}$. Se $r_{\mathrm{m}}=r_{\mathrm{k}}-t$ para poros cilíndricos, conhecendo-se o valor de $t$ e de $r_{\mathrm{m}}$, pode-se obter o valor do raio do poro $r_{\mathrm{k}}$ por meio da Equação de Kelvin. Para cada decréscimo de pressão, pode-se então relacionar o volume do poro com o diâmetro e, com vários pontos, obtém-se um diagrama de volume de poro versus diâmetro de poro, que caracteriza a distribuição de tamanhos de poro.

Este método apresenta as mesmas limitações que a equação de Kelvin, já que o cálculo do raio do poro utiliza essa equação.

\section{Porosimetria por intrusão de mercúrio}

A porosimetria por intrusão de mercúrio é uma técnica importante para a descrição quantitativa da estrutura porosa de um sólido 29

Essa técnica se desenvolveu a partir da observação do comportamento de um líquido sobre um sólido poroso, o qual não é molhado pelo líquido em questão a pressão atmosférica. A primeira equação que descrevia esse comportamento foi desenvolvida por Washburn em 1921 e tem o nome de seu ator (Equação 23) ${ }^{15}$.

$$
D=-4 \gamma \cos \theta / P
$$

(Equação 23)

onde: $D=$ diâmetro do poro

$\gamma=$ tensão superficial do líquido

$\theta=$ ângulo de contato entre o líquido e o sólido

$P=$ pressão

Essa equação é capaz de descrever o comportamento do mercúrio na superfície de um sólido e pode também ser expressa em função do raio $r$ do poro, bastando dividi-la pelo fator 2. Não sendo capaz de molhar a maioria dos sólidos conhecidos, o mercúrio só penetra nos poros dos materiais com aplicação de pressão, que será tão mais alta quanto menor for o tamanho do poro. A tensão superficial do mercúrio é alta, cerca de $485 \mathrm{dina} / \mathrm{cm}^{3}$. Esse valor alto mostra a tendência do líquido em se contrair para uma forma de área específica mínima, como resultado de forças intermoleculares em sua superfície. Por essa razão, o mercúrio apresenta ângulos de contato muito altos com a maioria dos sólidos (em torno de $130^{\circ}$ ). Todas essas características fazem com que o mercúrio seja o único líquido utilizado na porosimetria por intrusão ${ }^{15,29}$.

A desvantagem da aplicação da Equação 23 está no fato de os poros não serem normalmente circulares, levando assim a resultados somente comparativos. Outras desvantagens são observadas quando poros com formato "pote de tinta" estão presentes, pois a pressão necessária à penetração do mercúrio será função apenas do diâmetro da abertura do poro. Observam-se ainda desvios devido à compressão tanto do mercúrio quanto da amostra nas pressões utilizadas. Alguns artifícios são empregados com o objetivo de diminuir tais distorções. $\mathrm{O}$ ensaio em branco pode ser usado para eliminar o efeito de compressão do mercúrio, enquanto que tratamentos matemáticos que levam em consideração o módulo de compressão da amostra melhoram os resultados distorcidos por esse fator ${ }^{13,29}$.

A distribuição de tamanhos de poro pode ser obtida pela porosimetria por intrusão de mercúrio por meio da medida do volume de mercúrio penetrado a uma dada pressão. O volume de mercúrio é determinado pela diferença no nível de mercúrio em contato com o fluido que exerce a pressão. Normalmente, observa-se um aumento brusco do volume cumulativo de mercúrio no início do processo devido ao preenchimento dos espaços intersticiais. Portanto, a determinação da distribuição de tamanhos de poro não deve levar em consideração os primeiros valores de volume cumulativo em função da pressão ${ }^{13}$.

A distribuição de tamanhos de poro pode ser dada pelas funções de distribuição $d V / d r, d V / d \log r$ ou $d V / d \ln r$ em função do raio do poro, onde $d V$ é a variação de volume de poros quando o raio de um poro cilíndrico varia de $r$ a $r-d r$. Normalmente, as funções logarítmicas são utilizadas por reduzir a grande faixa de valores de volume que deve ser utilizada no caso da primeira função. Nos gráficos de distribuição $d V /$ $d r, d V / d \ln r$ e $d V / d \log r$ versus $r$, a altura da curva em qualquer ponto ao longo do eixo de $r$ reflete não só o volume de intrusão naquele ponto, mas também o fato de que o valor numérico da função é determinado pela pressão na qual aquele volume penetrou ${ }^{30,31}$.

A escolha do método mais apropriado para a determinação da distribuição de tamanhos de poro deve ser baseada no tipo de porosidade apresentado pelo material. No caso dos copolímeros à base de divinilbenzeno, a porosidade pode ser prevista por meio dos parâmetros de síntese. Para tanto, torna-se necessário o conhecimento do mecanismo de formação da estrutura porosa desses materiais, assim como as variáveis reacionais que afetam esse mecanismo.

\section{POROSIDADE EM COPOLÍMEROS À BASE DE DIVINILBENZENO}

A utilização de suportes poliméricos macroporosos se iniciou em 1962, quando Kunin e colaboradores ${ }^{32}$ relataram uma nova técnica de polimerização. Essa técnica dava origem a resinas de troca iônica com propriedades totalmente diferentes das resinas convencionais (tipo gel) até então produzidas. Esses materiais apresentavam uma porosidade permanente, similar à da sílica. A técnica descrita envolvia a copolimerização em suspensão de estireno com divinilbenzeno em presença de um composto diluente capaz de solubilizar os monômeros e com baixa capacidade para inchar o copolímero resultante. As resinas macroporosas obtidas possuíam uma estrutura porosa não-gel (macroporosa), que não colapsava após a secagem como acontecia com a resina do tipo gel, e possuíam atividade catalítica, quando funcionalizadas, superior à de resinas convencionais (tipo gel).

Kun e Kunin ${ }^{7}$ definiram a estrutura macroporosa como sendo constituída de uma porosidade não-gel (porosidade permanente) em adição à porosidade gel. A resina gel se apresenta como uma fase polimérica contínua, enquanto que a macroporosa apresenta canais entre os aglomerados de microesferas distribuídos, aleatoriamente, na estrutura da resina.

Dusek $^{33}$ atribuiu a formação de estruturas não homogêneas durante a reticulação em alguns sistemas diluente-polímero à ocorrência de um processo de separação de fases, governado, predominantemente, por fatores termodinâmicos. Mostrou, por meio de relações matemáticas, que a reticulação do polímero solúvel no sistema diluente levava a um processo de sinérese após a separação de fases. A separação de fases é determinada principalmente pela concentração dos monômeros mono- e difuncional, pela concentração do diluente e por sua interação com os demais componentes do sistema.

Kun e Kunin ${ }^{34}$ propuseram um mecanismo de formação da estrutura macroporosa durante a polimerização em suspensão baseado em um processo em três estágios, no qual cada gota de fase orgânica (monômeros, diluente e iniciador) se comporta como uma polimerização em lama individual. Durante os primeiros estágios da polimerização, é formado um polímero constituído de cadeias lineares contendo grupos vinila pendentes. 
Com o decorrer da reação, são formados microgéis reticulados intramolecularmente e cadeias lineares de alto peso molecular solúveis na mistura monômero-diluente. A temperatura da reação, a concentração do agente de reticulação e do diluente determinam quando a separação de fases ocorrerá, originando uma fase rica em copolímero e outra rica em diluente. Os monômeros se encontram distribuídos entre essas duas fases. O copolímero precipita da fase rica em sua espécie na forma de esferas, devido à menor energia que esta forma apresenta, separando-se como uma massa de microesferas. A um certo grau de conversão ocorre a macrogelação, originando pérolas do tipo gel formadas pela aglomeração de microgéis. A macrogelação é o primeiro estágio na formação da estrutura macroporosa. No segundo estágio, ocorre a ligação das microesferas pela polimerização dos monômeros residuais que as solvatam. É neste estágio que a estrutura macroporosa se forma. No terceiro estágio, há a remoção do diluente por destilação, o que pode levar a um aumento da velocidade de polimerização.

A remoção do diluente pode ocorrer em dois estágios diferentes: ao final ou durante a reação de polimerização, gerando assim diferentes tipos de estrutura porosa.

Caso o diluente permaneça no gel durante toda a síntese e seja removido somente ao final da reação, ocorre a formação de uma rede polimérica expandida que colapsa com a saída do solvente, formando uma estrutura vítrea não porosa. A remoção do diluente durante a reação de polimerização pode acontecer antes ou após a etapa de macrogelação. No primeiro caso, há formação de uma dispersão do polímero na fase líquida, enquanto que no segundo caso ocorre a dispersão do líquido na fase polimérica. Em ambos os casos obtém-se uma rede heterogênea constituída de polímero e solvente. Com a remoção do solvente, são criados espaços na rede denominados poros, cujo tamanho varia de $10 \AA$ a $1 \mu \mathrm{m}^{35}$.

Muitos estudos têm sido feitos com o objetivo de correlacionar condições de síntese com estrutura porosa ${ }^{36-39}$. Os fatores determinantes na formação da porosidade são os que afetam diretamente a extensão da separação de fases. Entre esses estão a concentração do agente de reticulação, a relação entre a quantidade de diluente e de monômero (grau de diluição) e a afinidade do polímero pelo solvente, ou seja, o poder solvatante do diluente. A combinação desses fatores torna possível a obtenção de estruturas com a porosidade desejada para um determinado fim.

Sederel e De Jong ${ }^{8}$ relataram três métodos para a obtenção de estruturas porosas, de acordo com o tipo de diluente utilizado:

1) pela adição de um diluente solvatante, produzindo copolímeros com volumes de poros relativamente baixos $(<0,8$ $\mathrm{ml} / \mathrm{g})$, área específica considerável $\left(50-500 \mathrm{~m}^{2} / \mathrm{g}\right)$ e diâmetros médios de poro pequenos;

2) pela adição de um diluente não-solvatante, produzindo copolímeros com volumes de poros altos $(0,6-2,0 \mathrm{ml} / \mathrm{g})$, área específica na faixa de 10 a $100 \mathrm{~m}^{2} / \mathrm{g}$ e diâmetros médios de poro relativamente altos e

3) pela adição de um polímero linear, obtendo-se volumes de poros acima de $0,5 \mathrm{ml} / \mathrm{g}$, área específica na faixa de 0 a 10 $\mathrm{m}^{2} / \mathrm{g}$ e altos diâmetros médios de poro.

O mecanismo de formação dos poros quando se utiliza um polímero linear como agente porogênico foi estudado por Cheng et $\mathrm{al}^{30}$. Neste caso, o tamanho dos poros é função do grau de emaranhamento do polímero linear durante a reação. Quanto mais expandidas estiverem as cadeias do polímero, maiores serão os poros formados.

Em todos os casos, a porosidade final, que é determinada quando a rede polimérica está no estado gel, é função da estabilidade dos poros após a remoção do agente porogênico, seja ele um diluente solvatante, não solvantante ou um polímero linear. A estabilidade dos poros está intimamente ligada ao grau de homogeneidade da distribuição de ligações cruzadas pela rede polimérica.
Todos os métodos utilizados na caracterização da estrutura porosa utilizam o polímero no estado seco. A porosidade nesse caso é bastante diferente de quando o material se apresenta inchado pelo diluente. Com o objetivo de manter a porosidade no estado seco semelhante à do estado inchado, foi estudado um tratamento de secagem do polímero, fazendo-se mudanças sucessivas de solventes de forma a diminuir gradativamente a afinidade do solvente pelo polímero. Foi mostrado que copolímeros secos a partir de um não-solvente, como metanol, apresentam uma porosidade máxima semelhante à obtida no estado inchado, enquanto que copolímeros secos a partir de um bom solvente como tolueno apresentam poros parcial ou totalmente colapsados. A troca de um bom solvente por um de baixa afinidade faz com que a rede polimérica fique congelada na conformação mais expandida, mantendo essa porosidade no estado seco ${ }^{40}$.

Dentre os vários tipos de copolímeros reticulados por divinilbenzeno, os que apresentam estrutura macroporosa são os de maior interesse em processos de separação de metais ou de biomoléculas, como suportes para catalisadores, para imobilização de enzimas e outros usos ${ }^{30,41}$.

Desde o início dos estudos relacionados à técnica de obtenção de copolímeros macroporosos, as determinações da área específica e da distribuição de tamanhos de poros vem sendo dois dos principais parâmetros de acompanhamento e avaliação das estruturas formadas. Em 1962, quando Kunin et al. relataram a nova técnica de polimerização pela qual se obtinham resinas de troca iônica com porosidade permanente, os materiais já foram caracterizados quanto à área específica e diâmetro médio de poro pela técnica de adsorção de nitrogênio, sendo, desta forma, diferenciados dos materiais não porosos até então sintetizados $^{32}$. Vários estudos subseqüentes que se propunham a estudar o mecanismo de formação da estrutura porosa utilizavam as técnicas de adsorção de nitrogênio e porosimetria por intrusão de mercúrio para determinação da porosidade como uma ferramenta para caracterizar o material nos diferentes estágios da reação $7,8,12,22,34,42$. Após a elucidação do mecanismo pelo qual a estrutura porosa era formada, muitos esforços foram dedicados ao estudo da influência das condições de síntese sobre a porosidade final dos copolímeros à base de divinilbenzeno. Estudos sobre a natureza do diluente, o grau de diluição e o teor de agente reticulador foram feitos embasados também em determinações de propriedades porosas dos materiais $9,12,22,23,43-50$. A partir daí, passou-se a utilizar tais conhecimentos para se obter materiais com características porosas definidas para uma dada aplicação ${ }^{24,51,52}$.

Apesar da grande dependência de todo esse estudo pelos métodos de caracterização da estrutura porosa, há uma total ausência de trabalhos que se dediquem a estudar as técnicas de adsorção de nitrogênio e porosimetria de mercúrio para a caracterização de copolímeros à base de divinilbenzeno. Toda e qualquer citação dos métodos mostra que estes são usados apenas como uma ferramenta de apoio ao estudo de condições de síntese. Dentre os modelos matemáticos modernos desenvolvidos para melhorar a faixa de pressão relativa em que se aplique a equação de BET, nenhum considera como alvo a caracterização de copolímeros à base de divilbenzeno. Portanto, a condição normalmente escolhida para determinação da área específica nesses materiais é a adsorção de nitrogênio a uma temperatura de $77 \mathrm{~K}$, temperatura do nitrogênio líquido. Essa condição é a mesma utilizada para a maioria dos materiais, sendo o método de BET também empregado na determinação quantitativa da área nesses copolímeros. Na Figura 5 são apresentadas isotermas de dois copolímeros de estireno e divinilbenzeno com porosidades diferentes (Tabela 3) e na Figura 6 suas micrografias de microscopia eletrônica de varredura. Pode-se observar que as curvas de adsorção e dessorção de nitrogênio para esses materiais se assemelham a uma isoterma do quarto tipo, característica de materiais mesoporosos. Obser- 
va-se ainda que o fenômeno de histerese é mais acentuado para o copolímero com poros menores. Isso mostra que, neste caso, ocorre uma maior diferença entre os processos de condensação e evaporação do que quando o material apresenta poros de tamanhos maiores.

Os copolímeros A e B, apesar de apresentarem grande diferença no diâmetro médio de poros, apresentam valores de área específica praticamente iguais e apenas um pequeno aumento no volume de poros. Isto pode sugerir que o copolímero B

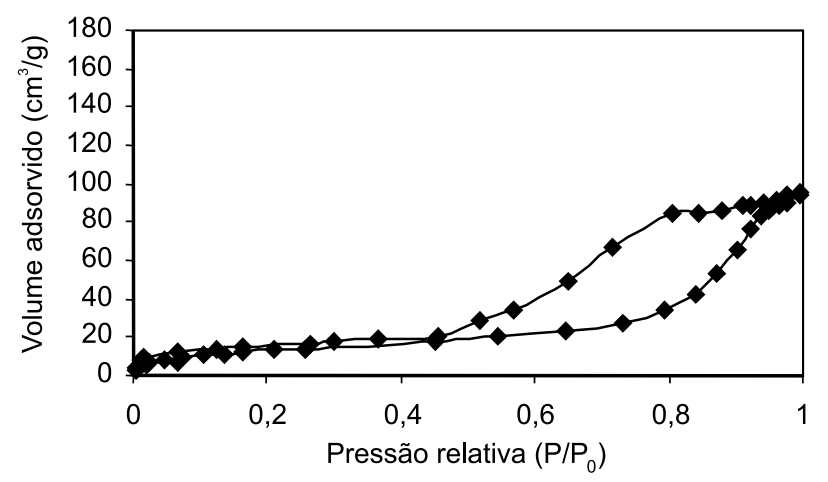

(a) apresenta poros mais largos e rasos que os do copolímero A e, consequentemente, um menor número de poros. Sendo assim, o aumento do diâmetro é compensado pelo aumento do volume de poros e as áreas específicas dos dois materiais são comparáveis. As relações entre área específica (A), volume (V) e diâmetro de poro (D) podem ser facilmente demonstradas pela Equação 24, pela qual observa-se que um pequeno aumento do volume contribui grandemente para o aumento do diâmetro de poros.

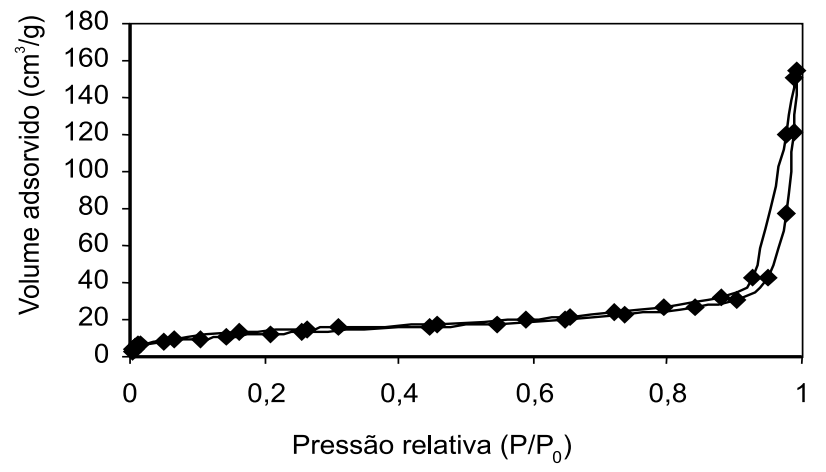

(b)

Figura 5. Isotermas dos copolímeros de estireno e divinilbenzeno $A(a) e B(b)$.
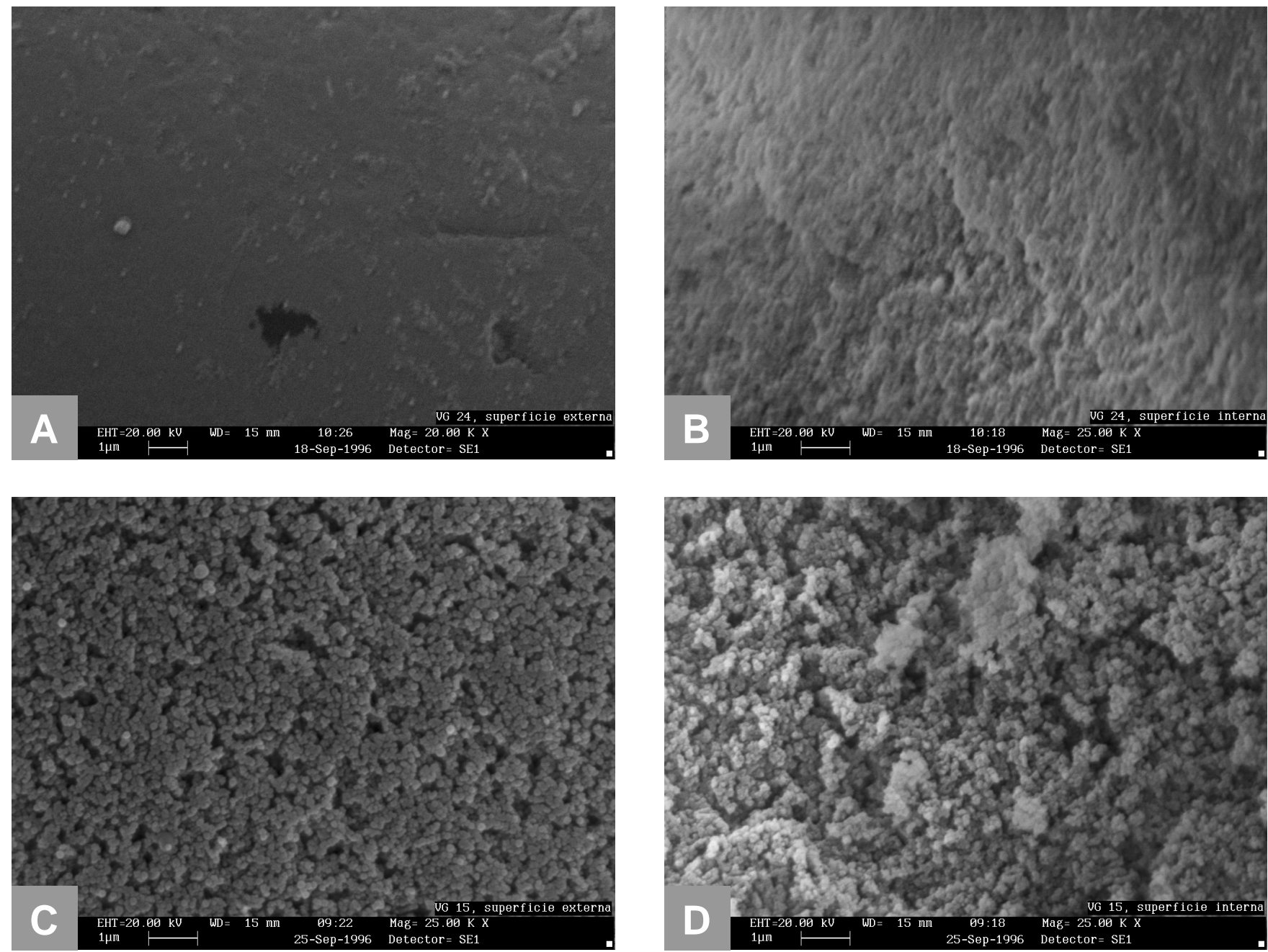

Figura 6. Micrografias de microscopia eletrônica de varredura do copolímero de estireno e divinilbenzeno A: superfície externa (A) $e$ superficie interna $(B)$ e do copolímero $B$ : superfície externa $(C)$ e superfície interna $(D)$. 
Tabela 3. Características porosas dos copolímeros de estireno e divinilbenzeno A e B

\begin{tabular}{cccc}
\hline Copolímero & $\begin{array}{c}\text { Área específica }\left(\mathrm{m}^{2} / \mathrm{g}\right) \\
(\text { método BET) }\end{array}$ & $\begin{array}{c}\text { Volume de poros }\left(\mathrm{cm}^{3} / \mathrm{g}\right) \\
(\text { método BJH) }\end{array}$ & $\begin{array}{c}\text { Diâmetro médio de poros } \\
(\AA)\end{array}$ \\
\hline A & 49,4 & 0,14 & 59 \\
B & 45,5 & 0,22 & 290 \\
\hline
\end{tabular}

$$
\mathrm{D}=\left(4 \times 10^{4} \mathrm{~V}\right) / \mathrm{A}
$$

O método comparativo entre uma isoterma padrão e a isoterma da amostra é muitas vezes utilizado no cálculo da área. Esse método semi-quantitativo, denominado $t$-plot, considera o fato de que cada sistema adsorvente-adsorvato apresenta uma isoterma de adsorção única. Portanto, materiais de mesma natureza química porém com valores de área específica diferentes apresentarão isotermas semelhantes. Uma isoterma padrão pode ser obtida por meio da adsorção do gás sobre um sólido não poroso e servirá como referência para comparação com outros materiais de mesma natureza. Entretanto, as isotermas padrão utilizadas não foram construídas empregando copolímeros à base de divinilbenzeno e sim materiais mais comuns, como catalisadores de base inorgânica e zeólitas entre outros ${ }^{15}$.

Dentre os métodos de determinação de distribuição de tamanhos de poro citados, a escolha do mais apropriado é função do tipo de porosidade apresentado pelo copolímero. A porosimetria por intrusão de mercúrio é a mais utilizada para a caracterização de copolímeros macroporosos, pois se aplica a poros com diâmetros de $30 \AA$ até milhares de ângstrons, se equipamentos de alta pressão forem utilizados ${ }^{15}$. A adsorção de nitrogênio utilizando o método BJH é mais aplicada na caracterização de copolímeros microporosos e mesoporosos com tamanhos de poro de até $400 \AA$, aproximadamente ${ }^{53}$. Este limite máximo para a adsorção de nitrogênio não leva a resultados muito confiáveis, devido às limitações impostas pela equação de Kelvin. Por isso, a porosimetria de mercúrio é normalmente preferida para a caracterização de sólidos mesoporosos. Já a caracterização de microporosidade é feita por adsorção de nitrogênio utilizando pressões relativas muito baixas, da ordem de $10^{-3}$ a $10^{-6} 22$. A caracterização desse tipo de porosidade por intrusão de mercúrio exige pressões muito altas. Para poros com diâmetros menores que $30 \AA$ são necessárias pressões maiores que $414 \mathrm{MPa}$ ou 60.000 psia, o que torna o método nada atrativo.

Uma desvantagem da porosimetria por intrusão de mercúrio é a possível quebra das pérolas de copolímero pela alta pressão imposta. Copolímeros macroporosos são naturalmente frágeis devido à sua morfologia. Muitas vezes a caracterização dos poros menores é comprometida devido à quebra provocada pela intrusão do mercúrio a altas pressões. Assim, a associação dos dois métodos se mostra uma boa solução para caracterizar toda a faixa de diâmetros de poros nos copolímeros.

Uma forma simples de se expressar a porosidade total de copolímeros à base de divinilbenzeno é pelo cálculo do percentual de porosidade, que representa a fração de poros contida no copolímero:

$$
p \%=\left(1-\rho_{0} / \rho_{\mathrm{a}}\right) \times 100
$$

(Equação 25)

onde $\rho_{0}$ e $\rho_{a}$ são a densidade aparente do copolímero poroso e a densidade aparente do copolímero homogêneo, respectivamente.

$\mathrm{O}$ volume cumulativo de poro $V_{\mathrm{p}}$ pode também ser calculado facilmente por meio da Equação 26 e se aproxima, com bastante confiança, do volume obtido pelos métodos instrumentais.

$$
V_{\mathrm{p}}=1 / \rho_{\mathrm{a}}-1 / \rho_{0}
$$

(Equação 26)

$\mathrm{O}$ volume de poros fixos, definido como o volume relativo aos poros que não colapsam após a remoção do diluente, pode também ser determinado pelo volume de água retido por massa de copolímero, se este não tiver capacidade de inchar em água. Este teste deve ser realizado após tratamento do copolímero com metanol, que reduz a hidrofobicidade de sua superfície e permite a penetração da água através dos poros. Exceto para volumes de poros muito pequenos, este método apresenta um erro experimental inferior a $3 \%{ }^{10,54}$.

$O$ percentual de porosidade e o volume de poros são parâmetros de fácil e rápida obtenção que levam a uma idéia da relação entre a porosidade de várias amostras diferentes ${ }^{30,31}$.

A propriedade de inchamento dos copolímeros reticulados com divinilbenzeno na presença de solventes de diferentes afinidades pode também ser de grande valia na caracterização de sua estrutura porosa. A determinação dessa propriedade, associada ou não à determinação das características porosas por adsorção de nitrogênio ou porosimetria de mercúrio, foi um dos parâmetros mais utilizados nos primeiros estudos sobre a formação da estrutura porosa de copolímeros à base de divinilbenzeno $7,34,55,56$. Mais recentemente, Rabelo ${ }^{57}$ classificou, em quatro tipos diferentes, a estrutura porosa de copolímeros à base de estireno e divinilbenzeno em função do seu grau de inchamento em heptano, solvente de baixa afinidade pelo copolímero. A quantidade de heptano absorvida pelas pérolas, resultado do preenchimento dos poros fixos e da expansão desses poros, levou à classificação dos copolímeros em: tipo gel, colapsado, macroporoso/colapsado ou macroporoso. O inchamento em um solvente de alta afinidade pelo material, como tolueno, é também o resultado das mesmas contribuições que em heptano, porém acrescido do inchamento dos núcleos poliméricos (fase gel). A diferença entre as quantidades absorvidas nos dois casos serve como uma referência da capacidade de inchamento da fase gel de copolímeros com diferentes estruturas porosas.

$\mathrm{O}$ estudo da estrutura porosa é, normalmente, acompanhado pela análise da topografia do material por microscopia eletrônica de varredura. Esta técnica propicia a visualização do tamanho e da distribuição dos agregados de microesferas na superfície das pérolas do copolímero. Aumentos da ordem de 5.000 vezes já são suficientes para diferenciar estruturas porosas, enquanto que aumentos de, aproximadamente, 20.000 vezes permitem uma visualização detalhada das superfícies interna e externa das pérolas ${ }^{58-60}$.

\section{CONCLUSÃO}

A intrusão de mercúrio e a adsorção de gases apresentam-se como dois princípios diferentes que podem ser utilizados para caracterizar os principais parâmetros de porosidade de um sólido, que são a área específica e a distribuição de tamanhos de poro. Justamente por lidarem com interações físicas distintas, os resultados obtidos por esses métodos podem apresentar algumas discrepâncias. Entretanto, deve-se procurar utilizar ambos os métodos de forma complementar, respeitando-se as limitações de cada um. 
Para a caracterização de copolímeros à base de divinilbenzeno, são ainda necessários estudos a respeito de melhores condições de análise, já que os métodos desenvolvidos para caracterização de estruturas porosas não têm como alvo este tipo de material.

\section{REFERÊNCIAS}

1. Alexandratos, S. D.; Crick, D. W.; Ind. Eng. Chem. Res. 1996, 35, 635

2. Beauvais, R. A.; Alexandratos, S. D.; React. Funct. Polym. 1998, 36, 113.

3. Belfer, S.; Egozy, Y.; Korngold, E.; J. Appl. Polym. Sci. 1984, 29, 3825

4. Teixeira; V. G.; Dissertação de Mestrado, Universidade Federal do Rio de Janeiro, 1997.

5. Fetscher, C. A.; Hills, S.; Lipowski, S. A.; Patente Americana 1967, $\mathrm{n}^{\mathrm{o}} 3.345 .344$.

6. Takeda, K.; Akiyama, M.; Kawakam, I. F.; Sasaki, M.; Bull. Chem. Soc. Jpn. 1986, 59, 2225.

7. Kun, K. A.; Kunin, R.; Polym. Letters 1964, 2, 587.

8. Sederel, W. L.; De jong, G. J; J. Appl. Polym. Sci. 1973 17,2835 .

9. Wieczorek, P. P.; Kolarz, B. N.; Galina. H.; Die Angw. Makromol. Chem. 1984, 126, 39.

10. Rabelo, D.; Tese de Doutorado, Universidade Federal do Rio de Janeiro, 1993.

11. Gregg, S. J.; Sing, K. S. W.; Adsorption, Surface Area and Porosity; Academic Press; London, 1982; p 41.

12. Howard, G. J.; Midgley, C. A.; J. Appl. Polym. Sci. 1981, 26, 3845.

13. Allen T.; Particle Size Measurement; Chapman and Hall; $4^{\text {th }}$ edition; London, 1990; p 456.

14. Yunes, S.; Explanation and Application of the Physisorption and the Chemisorption Techniques in the Characterization of Solids in General and Catalysts in Particular; Micromeritics Instruments Corp.; Norcross, 1998; p 5

15. Webb, P. A.; Orr, C.; Analytical Methods in Fine Particle Technology; Micromeritics Instruments Corp.; Norcross 1997; p 24.

16. Rudzinski, W.; Everett, D. H.; Adsorption of Gases on Heterogeneous Surfaces; Academic Press; London, 1992; p 98.

17. Brunauer, S.; Skalny, J.; Bodor, E. E; J. Colloid Interface Sci. 1969, 30, 546 .

18. McMillan, W. G.; Teller, E.; J. Chem. Phys. 1951, 19, 25.

19. Hill, T. L.; Ad. Catal. 1952, 4, 211.

20. Everett, D. H.; Langmuir 1990, 6, 1729.

21. Redhead, P. A.; Langmuir 1996, 12, 763.

22. Jacobelli, H.; Bartholin, M.; Guyot, A; J. Appl. Polym. Sci. 1979, 23, 927.

23. Djahièche, A.; Rabia, I.; Revillon, A.; Die Angew. Makromol. Chem. 1994, 222, 89.

24. Poinescu, I. C.; Vlad, C.; Polym. Plast. Technol. Eng. 1996, 35, 1, 31

25. Smith, D.; The Microreport 1996,7, 2, 8.

26. Dabrowski, A.; In Stud. Surf. Sci. Catal. - Part A: 120; Dabrowski, A., Ed.: Elsevier Science B. V. London, 1999; p 3 .
27. Barrett, E. P.; Joyner, L. G.; Halenda, P. P.; J. Am. Chem. Soc. 1951, 73, 373.

28. Harkins, W. D.; Jura, G; J. Am. Chem. Soc. 1944, 66, 1366.

29. Abrams, L.,; Maynard R.; Favorite, C.; The Microreport 1996, 7, 4, 1 .

30. Cheng, C. M.; Micale, F. J.; Vanderhoff, J. W.; El Aasser, M. S.; J. Polym. Sci.: part A: Polym. Chem. 1992, 30, 235.

31. Erbay, E.; Okay, O.; J. Appl. Polym. Sci. 1999, 71, 1055.

32. Kunin, R.; Meitzner E.; Bortnick, N; J. Am. Chem. Soc. 1962, 84, 305 .

33. Dusek, K.; Polym. Letters 1965, 3, 209.

34. Kun, K. A.; Kunin, R.; J. Polym. Sci.: part A 1968, 6, 2689.

35. Okay, O.; Polymer 1999, 40, 4117.

36. Rabelo, D.; Coutinho, F. M. B.; Polym. Bull. 1994, 33, 479.

37. Rabelo, D.; Coutinho, F. M. B.; Polym. Bull. 1994, 33, 487.

38. Rabelo, D.; Coutinho, F. M. B.; Polym. Bull. 1994, 33, 493.

39. Coutinho, F. M. B.; Teixeira, V. G.; Barbosa, C. R.; J. Appl. Polym. Sci. 1998, 67, 781.

40. Erbay, E.; Okay, O.; Polym. Bull. 1998, 41, 379.

41. Huxham, I. M.; Makromol. Chem. 1991, 192, 1695.

42. Hilgen,, H.; de Jong, G. J.; Sedere, W. L.; J. Appl. Polym. Sci. 1975, 19, 2647.

43. Wójcik, A. B.; Die Angew. Makromol. Chem. 1983, 119, 193.

44. Poinescu, I. C.; Beldie, C.; Vlad, C.; J. Appl. Polym. Sci. 1984, 29, 23.

45. Okay, O.; Soner, E.; Balkas, T. I.; J. Appl. Polym. Sci. 1985, 30, 2065.

46. Okay, O.; Balkas, T. I.; J. Appl. Polym. Sci. 1986, 31, 1785.

47. Okay, O.; Die Angew. Makromol. Chem. 1987, 153, 125. 48. Okay, O.; Die Angew. Makromol. Chem. 1988, 157, 15.

49. Poinescu, I. C.; Beldie, C.; Die Angew. Makromol. Chem. 1988, 164, 45.

50. Thomson, B.; Rudin, A.; Lajoie, G.; J. Appl. Polym. Sci. 1996, 59, 2009.

51. Christensen, B. E.; Myhr, M. H.; Aune, O.; Hagen, S.; Berge, A.; Ugelstad, J.; Carbohidr. Polym. 1996, 29, 217.

52. Moustafa, A. B.; Faizalla, A.; J. Appl. Polym. Sci. 1999, $73,149$.

53. Olivier J. P.; The Microreport 1997, 8, 1, 1.

54. Rabelo, D.; Coutinho, F. M. B.; Polym. Bull. 1993, 30, 725.

55. Millar, J. R.; Smith, D. G.; Marr, W. E.; Kressman, T. R. E.; J. Chem. Soc. 1963, 218.

56. Millar, J. R.; Smith, D. G.; Kressman, T. R. E.; J. Chem. Soc. 1965, 304.

57. Rabelo, D.; Coutinho, F. M. B.; Eur. Polym. J. 1994, 6, 675.

58. Coutinho, F. M. B.; Rabelo, D.; Eur. Polym. J. 1992, 28, 12,1553

59. Rabelo, D.; Coutinho, F. M. B.; Barbosa, C. C. R.; Rezende, S. M.; Polym. Bull. 1995, 34, 621.

60. Barbosa, C. C. R.; Cunha, J. W. S. D.; Teixeira, V. G.; Coutinho, F. M. B.; Polímeros: Ciência e Tecnologia 1998, 4, 31 . 